\title{
Effects of caregiver burden on quality of life and coping strategies utilized by caregivers of adult patients with inflammatory bowel disease
}

\author{
Nimisha K. Parekha, Shamita Shah ${ }^{b}$, Kristin McMastera, Alissa Spezialec, Laura Yund, \\ Douglas L. Nguyen ${ }^{a}$, Gil Melmede, Sunanda Kane ${ }^{f}$ \\ University of California Irvine; Oschner Clinic; Sharp Rees Medical Center; Northwestern University; Cedar Sinai \\ Medical Center; Mayo Clinic, USA
}

\section{Abstract}

\begin{abstract}
Background While previous studies have evaluated caregivers' quality of life (QOL), burnout, and stress amongst across a variety of chronic illnesses, few such studies have been related to inflammatory bowel disease (IBD).
\end{abstract}

\begin{abstract}
Methods Caregivers accompanying adult patients with IBD at 6 tertiary centers were enrolled. They completed self-administered surveys related to QOL and burden, including the QOL scale,
\end{abstract} Zarit Burden Interview (ZBI), and Brief COPE.

Results Of the 200 consecutive caregivers asked to participate, 162 (81.0\%) enrolled and completed the survey. A total of $43.8 \%$ caregivers reported having a high level of burden as measured by the ZBI. Factors predictive of a high burden included female gender, younger age of caregiver, household income $<\$ 30,000$, having more than one dependent in the household, caring for a patient with active disease and higher disease severity, and a personal history of psychiatric illness. Over one third of the caregivers reported a maladaptive coping pattern. The caregiver factors predictive of maladaptive coping skills included male gender, lack of involvement in a support group, a personal history of psychiatric illness, and living in a different household from the patient.

Conclusions A large proportion of caregivers of IBD patients experience a high level of caregiver burden and reduced QOL. Participation in religious/spiritual activities and support groups appeared to reduce perceived caregiver burden and improve QOL. This study suggests there is an unmet need to address the caregiver burden of adult IBD patients.

Keywords Caregiver burden, quality of life, inflammatory bowel disease

Ann Gastroenterol 2016; 29 (4): 1-7

\section{Introduction}

Inflammatory bowel disease (IBD), including Crohn's disease (CD) and ulcerative colitis (UC), is a chronic

\footnotetext{
anniversity of California Irvine (Nimisha K. Parekh, Kristin McMaster, Douglas L. Nguyen); ' Oschner Clinic (Shamita Shah); 'Sharp Rees Medical Center (Alissa Speziale); ${ }^{d}$ Northwestern University (Laura Yun); ${ }^{\mathrm{e} C e d a r ~ S i n a i ~ M e d i c a l ~ C e n t e r ~(G i l ~ M e l m e d) ; ~}{ }^{\mathrm{f}}$ Mayo Clinic (Sunanda Kane), USA

Conflict of Interest: None

Correspondence to: Nimisha A Parekh, MD/MPH, Director of the Inflammatory Bowel Disease Program, Department of Medicine, UC Irvine School of Medicine, 333 City Blvd. West, Suite 400, Orange, CA 92868, Tel.: +1 714456 6745, Fax: +1 714456 7753,

e-mail: parekhn@uci.edu
}

Received 29 May 2016; accepted 18 July 2016; published online 6 September 2016

DOI: http://dx.doi.org/10.20524/aog.2016.0084

C 2016 Hellenic Society of Gastroenterology inflammatory disorder of the intestines that follows a remitting and relapsing clinical course. The annual incidence in Northern Europe and the United States is estimated to be from 2 to 11 per 100,000 for UC and 1 to 6 per 100,000 for CD [1,2]. A diagnosis of chronic illness such as IBD can be devastating, and often results in feelings of hostility, despair, and grief [3]. These psychological effects extend beyond the initial diagnosis and may lead to long-term psychological impairments that shape the daily life of an individual with IBD. It is well established that several psychosocial issues impact the quality of life (QOL) of IBD patients, including loss of energy, loss of control, poor body image, feelings of isolation or fear, feeling a burden, and inability to reach full personal capacity $[4,5]$.

Chronic illnesses not only affect the individual patient, but also have a significant impact on the family unit [6-8]. A chronic illness, such as IBD, can completely disrupt a family's ability to function normally and often imposes a strain on family members' relationships [6]. During times of flareup, family members and friends often become caregivers for www.annalsgastro.gr 
the adult IBD patients. Given that IBD is currently a lifelong disease, caregivers face the challenge of learning to adapt to this disease throughout their lifespan. It has been shown that long-term chronic illnesses create an even greater burden on the family in comparison to acute illnesses [9]. Caregivers of patients with chronic physical illnesses often experience feelings of isolation and fatigue related to their increased responsibilities and challenges [8].

There has been significant research evaluating the caregiver's QOL, stress, and burnout, in relation to other chronic physical and mental health illnesses that show similarly deleterious effects $[7,8]$. Caregivers' well-being is an area of interest because of its potential impact on patients' long-term outcomes $[10,11]$. Although some studies have examined the relationship between family functioning and parental stress among caregivers of pediatric IBD patients [12-14], there is limited knowledge concerning the QOL of caregivers, the level of burden, and coping mechanisms among caregivers of adult patients with IBD. An improved understanding of these factors would allow healthcare providers to better serve this population and to provide adequate psychosocial interventions to assist these patients and their caregivers. Accordingly, this study aimed to assess caregiver burden as it relates to QOL and coping among caregivers of adult patients with IBD.

\section{Materials and methods}

\section{Subject recruitment and data collection}

The primary caregivers identified by adult IBD patients (age $\geq 18$ years) who were present at an outpatient encounter at six tertiary institutions between December 2010 and June 2011 were asked to participate. Caregivers were asked to complete an anonymous self-administered survey comprising 4 separate questionnaires:

1) General demographic information: participants were asked to complete personal demographic data, such as age, relationship to patient, gender, ethnicity, and total household income.

2) QOL index: a 33-question survey developed by Ferrans and Powers to measure QOL [15]. It evaluates four different domains: health and functioning, social and economic, psychological/spiritual, and family. The overall QOL score ranges from 0 to 30 , with 30 being the best.

3) Zarit Burden Interview (ZBI): a 22-question survey, each rated 0-9 (9-highest level of burden), measuring the physical, emotional, and financial toll of providing care [16]. A score $\geq 21$ has been defined in the ZBI as representing a high level of caregiver burden $[11,16]$.

4) Brief COPE: a 28-question survey evaluating 14 separate coping mechanisms (Table 1). Participants were asked to rate their responses on a scale from 1-4 (1=I haven't been doing this at all, to $4=\mathrm{I}$ have been doing this a lot). The total composite score for adaptive versus maladaptive coping was calculated for each participant and divided
Table 1 Brief COPE questionnaire assessing 14 different coping skills

Adaptive coping skills
1) Adaptive coping: I’ve been concentrating my efforts on doing
something about the situation I am in
2) Planning: I’ve been thinking hard about what steps to take
3) Use of emotional support: I've been getting emotional support
from others
4) Use of instrumental support: I've been getting help from other
people
5) Positive reframing: I've been trying to see it in a different light
and make it seem more positive
6) Acceptance: I've been accepting the reality of the fact that it has
happened
7) Religion: I've been trying to find comfort in my religion or
spiritual beliefs
8) Humor: I've been making jokes about it
Maladaptive coping skills
1) Venting: I've been expressing my negative feelings
2) Denial: I've been saying to myself this isn't real
6) Self-blame: I've been blaming myself for things that happened
me get through
4) Behavioral disengagement: I've been giving up trying to deal
with it
5) Self-distraction: I've been turning to work or other activities to
(ake my mind off of things

by the total components in the maladaptive and adaptive subscales $[17,18]$.

After the surveys were completed, information was collected onto a single spreadsheet at the lead site with double entry. All participant information was de-identified. The protocol was approved by the Institutional Review Board at each of the participating institutions.

\section{Statistical analyses}

Mean scores on the QOL index and ZBI were compared between subgroups identified according to the participants' characteristics, using t-tests and analysis of variance. A multivariate analysis was performed to identify characteristics that predicted those who were likely to utilize a predominantly adaptive coping strategy. In the final model, a P-value $<0.05$ was considered statistically significant.

\section{Results}

\section{General demographics}

Of the 200 consecutive caregivers asked to participate, $162(81.0 \%)$ consented and completed the survey. The overall 
characteristics of the IBD caregivers are summarized in Table 2 . The mean age was $49.6 \pm 14.6$ years old with a female predominance (66.9\%). A majority of the participants (54.3\%) had a minimum educational level of high school graduation, with nearly one third (29.7\%) having a college or graduate degree. A total of $66.0 \%$ of caregivers were working outside of the home on either a full-time or part-time basis. Only a minority of the caregivers (3.2\%) reported having to stop working because of caregiving to the patients. Over half (55.6\%) of the caregivers reported being either the patient's spouse or significant other, $22.5 \%$ reported being a parent, and $16.9 \%$ reported being a child. Approximately one third $(31.1 \%)$ stated that in addition to the patient, they also had at least 1 dependent living at home. Over half reported a total annual household income of greater then $\$ 100,000$. The caregivers reported that $58.0 \%$ of their patients had CD, while the reminder had either UC $(36.3 \%)$ or indeterminate colitis (5.7\%).

\section{QOL among IBD caregivers}

In this cohort, the mean QOL score was 19.89 \pm 12.15 . Participants with a QOL index of less than the mean of 19.89 were identified as having a lower QOL. In this cohort, factors associated with a lower QOL among IBD caregivers included (Table 3): presence of a dependent (other than the patient) in the household, caring for patients with active IBD exacerbation and higher disease severity, and a personal history of psychiatric illness. In contrast, factors not predictive of a lower QOL among caregivers were gender, ethnicity, age, household income, patient's IBD subtype, relationship to patient, and patient's involvement in a support group. Interestingly, the two factors predictive of a better QOL for caregivers were participation in religious or spiritual activities and attendance at a support group.

\section{Factors predictive of high caregiver burden}

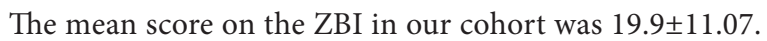
A total of 71 of the $162(43.8 \%)$ caregivers reported having a high level of burden, as measured by a ZBI score of $\geq 21[11,16]$. Table 4 summarizes the factors predictive of a high burden among caregivers of IBD patients. Factors predictive of a higher degree of caregiver burden included female gender, younger age, annual income level $<\$ 30,000$, having more than one dependent in the household (other than the patient), caring for a patient with active disease exacerbation or more severe disease, and a personal history of psychiatric illness. Participation in religious activities (ZBI $17.94 \pm 11.33$ vs. $22.13 \pm 14.05 ; \mathrm{P}=0.41$ ) and attendance at a support group $(18.29 \pm 12.37$ vs. $23.67 \pm 13.06 ; \mathrm{P}=0.035)$ were predictive of reduced level of burden. Duration served as caregiver, ethnicity, relationship to patient, and living in the same household as the patient were not predictive of a high level of burden.
Table 2 General demographics of primary caregivers of adult patients with inflammatory bowel disease

\begin{tabular}{|c|c|}
\hline Mean age (years) & $49.6 \pm 14.6(\%)$ \\
\hline \multicolumn{2}{|l|}{ Gender } \\
\hline Male & $53(33.1)$ \\
\hline Female & $107(66.9)$ \\
\hline \multicolumn{2}{|l|}{ Ethnicity } \\
\hline Caucasian/white & $127(79.4)$ \\
\hline Asian/Pacific islander & $10(6.3)$ \\
\hline Hispanic/Latino & $9(5.6)$ \\
\hline Other & $14(8.7)$ \\
\hline \multicolumn{2}{|l|}{ Current marital status } \\
\hline Married & $142(87.7)$ \\
\hline Cohabitation (not married) & $4(2.5)$ \\
\hline Single (never married) & $10(6.2)$ \\
\hline Separated/divorced & $6(3.7)$ \\
\hline \multicolumn{2}{|l|}{ Highest level of education } \\
\hline Middle school & $26(16.0)$ \\
\hline High school & $88(54.3)$ \\
\hline College degree & $40(24.7)$ \\
\hline Graduate degree & $8(5.0)$ \\
\hline \multicolumn{2}{|l|}{ Current employment status } \\
\hline Employed full-time & $76(46.9)$ \\
\hline Employed part-time & $31(19.1)$ \\
\hline Retired & $22(13.6)$ \\
\hline Stopped working because of caregiving & $5(3.2)$ \\
\hline Other & $28(17.2)$ \\
\hline \multicolumn{2}{|l|}{ Relationship to IBD patient } \\
\hline Spouse & $81(50.6)$ \\
\hline Significant other (not married) & $8(5.0)$ \\
\hline Parent & $36(22.5)$ \\
\hline Child & $27(16.9)$ \\
\hline Sibling & $2(1.3)$ \\
\hline Friend & $2(1.3)$ \\
\hline Other & $4(2.4)$ \\
\hline \multicolumn{2}{|l|}{ Total annual household income } \\
\hline Less than 10,000 & $5(3.2)$ \\
\hline$\$ 10,000-30,000$ & $16(10.2)$ \\
\hline$\$ 40,000-60,000$ & $24(15.3)$ \\
\hline$\$ 70,000-90,000$ & $31(19.7)$ \\
\hline Greater than $\$ 100,000$ & $81(51.6)$ \\
\hline More than 1 dependent living at home & $50(31.1)$ \\
\hline Personal history of psychiatric illness & $32(19.7)$ \\
\hline \multicolumn{2}{|l|}{ Type of IBD loved one has } \\
\hline Ulcerative colitis & $57(36.3)$ \\
\hline Crohn's disease & $91(58.0)$ \\
\hline Indeterminate colitis & $9(5.7)$ \\
\hline
\end{tabular}


Table 3 Factors associated with lower quality of life among caregivers of inflammatory bowel disease (IBD) patients $(\mathrm{N}=162)$

\begin{tabular}{|c|c|c|}
\hline Factors & $\begin{array}{l}\text { Quality-of-life } \\
\text { scale }\end{array}$ & P-value \\
\hline Gender & & 0.138 \\
\hline Male & $18.22 \pm 11.58$ & \\
\hline Female & $21.57 \pm 14.05$ & \\
\hline Ethnicity & & 0.659 \\
\hline Caucasian & $20.29 \pm 13.10$ & \\
\hline Non-Caucasian & $21.44 \pm 14.14$ & \\
\hline Age & & 0.674 \\
\hline$\leq 50$ years old & $20.78 \pm 12.90$ & \\
\hline$>50$ years old & $19.89 \pm 13.80$ & \\
\hline Income & & 0.047 \\
\hline Less than $\$ 30,000$ & $19.65 \pm 14.24$ & \\
\hline$\$ 40,000-60,000$ & $19.68 \pm 12.77$ & \\
\hline$\$ 70,000-90,000$ & $19.67 \pm 12.90$ & \\
\hline Greater than $\$ 100,000$ & $22.94 \pm 12.67$ & \\
\hline Dependents at home & & 0.013 \\
\hline None & $24.01 \pm 13.37$ & \\
\hline More than 1 dependent & $18.48 \pm 12.62$ & \\
\hline $\begin{array}{l}\text { Involvement in religious/ } \\
\text { spiritual activity }\end{array}$ & & 0.041 \\
\hline Yes & $22.13 \pm 14.35$ & \\
\hline No & $17.94 \pm 11.33$ & \\
\hline Subtype of IBD & & 0.716 \\
\hline Ulcerative colitis & $20.19 \pm 10.62$ & \\
\hline Crohn's disease & $20.99 \pm 14.11$ & \\
\hline Disease activity at time of survey & & 0.001 \\
\hline Active flaring & $18.94 \pm 12.98$ & \\
\hline In remission & $21.16 \pm 13.13$ & \\
\hline Disease severity & & 0.001 \\
\hline Mild & $25.59 \pm 15.39$ & \\
\hline Moderate & $21.87 \pm 13.62$ & \\
\hline Severe & $14.73 \pm 9.34$ & \\
\hline Years caring for IBD patient & & 0.981 \\
\hline$\leq 5$ years & $21.03 \pm 14.80$ & \\
\hline$>5$ years & $20.98 \pm 12.11$ & \\
\hline Relationship with patient & & 0.658 \\
\hline Spouse & $20.64 \pm 13.44$ & \\
\hline Parent & $21.38 \pm 14.08$ & \\
\hline Child & $21.38 \pm 13.35$ & \\
\hline Other & $16.53 \pm 10.31$ & \\
\hline $\begin{array}{l}\text { Ever diagnosed with psychiatric } \\
\text { illness }\end{array}$ & & 0.024 \\
\hline
\end{tabular}

(Contd...)
Table 3 Continued....

\begin{tabular}{llc}
\hline Factors & $\begin{array}{c}\text { Quality-of-life } \\
\text { scale }\end{array}$ & P-value \\
\hline Yes & $23.84 \pm 15.43$ & \\
\hline No & $19.50 \pm 12.43$ & \\
$\begin{array}{l}\text { IBD patient attends support } \\
\text { group }\end{array}$ & 0.624 \\
Yes & $21.84 \pm 13.05$ & \\
\hline No & $20.32 \pm 13.37$ & \\
\hline $\begin{array}{l}\text { Personally attends support } \\
\text { group }\end{array}$ & & 0.035 \\
\hline Yes & & \\
\hline No & $23.67 \pm 13.06$ & \\
\hline
\end{tabular}

\section{Coping patterns of IBD caregivers}

In our cohort, 105 of 162 caregivers (64.8\%) used predominantly adaptive coping patterns while the remaining $57(35.2 \%)$ employed maladaptive coping patterns. The caregiver factors predictive of maladaptive coping skills included male gender (OR 3.89, 95\% CI 2.49-6.07), lack of involvement in religious activity (OR 2.38, 95\% CI 1.23-4.61) or attendance at a support group (OR 3.88, 95\% CI 1.84-17.87), a personal history of psychiatric illness (OR 2.76, 95\% CI 1.25-6.05), and living in a different household from the patient (OR 95\%, CI 3.56 1.74-7.27). Caregiver characteristics of ethnicity, education level, total household income, age, years caring for the patient, and relationship to patient were not predictive of the coping patterns adopted by the caregivers (data not shown).

\section{Discussion}

The presence of IBD in the home can have a long-term impact on family members and may affect their overall QOL. Recent studies suggest that household members of IBD patients have mental disorders more frequently compared with the general population [19-22]. In contrast to previous studies that examined the impact of IBD on parents of children and adolescents $[13,21]$, our study is one of the first large-scale, multi-institutional studies to evaluate the impact of an adult IBD patient on the family unit from a caregiver's perspective. In our study, the factors associated with a lower QOL among IBD caregivers included the presence of a dependent (other than the patient) in the household, caring for patients with active IBD exacerbation, higher baseline disease severity, and a personal history of psychiatric illness. This is similar to previous findings for caregivers of patients with other chronic illnesses $[6,7,9]$. Our findings suggest an increased level of support is needed during times of disease exacerbation and, more generally, when the patient has a higher degree of disease severity. A better knowledge of the factors that impact 
Table 4 Factors predictive of a high level of burden among caregivers of inflammatory bowel disease (IBD) patients ( $\mathrm{N}=162)$

\begin{tabular}{|c|c|}
\hline & Zarit burden score \\
\hline \multicolumn{2}{|l|}{ Gender } \\
\hline Male & $18.22 \pm 11.58$ \\
\hline Female & $21.57 \pm 14.05$ \\
\hline \multicolumn{2}{|l|}{ Ethnicity } \\
\hline Caucasian & $20.29 \pm 13.10$ \\
\hline Non-Caucasian & $20.44 \pm 14.14$ \\
\hline \multicolumn{2}{|l|}{ Age } \\
\hline$\leq 50$ years old & $21.78 \pm 12.90$ \\
\hline$>50$ years old & $19.89 \pm 13.80$ \\
\hline \multicolumn{2}{|l|}{ Income } \\
\hline Less than $\$ 30,000$ & $22.94 \pm 12.67$ \\
\hline$\$ 40,000-60,000$ & $19.65 \pm 14.24$ \\
\hline$\$ 70,000-90,000$ & $19.68 \pm 12.77$ \\
\hline Greater than $\$ 100,000$ & $19.67 \pm 12.90$ \\
\hline \multicolumn{2}{|l|}{ Dependents at home } \\
\hline None & $24.01 \pm 13.37$ \\
\hline More than 1 dependent & $18.48 \pm 12.62$ \\
\hline \multicolumn{2}{|c|}{ Involvement in religious/spiritual activity } \\
\hline Yes & $17.94 \pm 11.33$ \\
\hline No & $22.13 \pm 14.35$ \\
\hline \multicolumn{2}{|l|}{ Subtype of IBD } \\
\hline Ulcerative colitis & $20.19 \pm 10.62$ \\
\hline Crohn's disease & $20.99 \pm 14.11$ \\
\hline \multicolumn{2}{|l|}{ Disease activity } \\
\hline Active flaring & $21.16 \pm 13.13$ \\
\hline In remission & $18.94 \pm 12.98$ \\
\hline \multicolumn{2}{|l|}{ Disease severity } \\
\hline Mild & $14.73 \pm 9.34$ \\
\hline Moderate & $21.87 \pm 13.62$ \\
\hline Severe & $25.59 \pm 15.39$ \\
\hline \multicolumn{2}{|l|}{ Years caring for IBD patient } \\
\hline$\leq 5$ years & $20.03 \pm 14.80$ \\
\hline$>5$ years & $20.98 \pm 12.11$ \\
\hline \multicolumn{2}{|l|}{ Relationship with patient } \\
\hline Spouse & $20.64 \pm 13.44$ \\
\hline Parent & $20.28 \pm 14.08$ \\
\hline Child & $20.38 \pm 13.35$ \\
\hline Other & $18.53 \pm 10.31$ \\
\hline \multicolumn{2}{|c|}{ Ever diagnosed with psychiatric illness } \\
\hline Yes & $23.84 \pm 15.43$ \\
\hline No & $19.50 \pm 12.43$ \\
\hline
\end{tabular}

(Contd...)
Table 4 Continued....

\begin{tabular}{cc}
\hline & Zarit burden score \\
\hline IBD patient attends support group & \\
Yes & $20.32 \pm 13.37$ \\
No & $21.84 \pm 13.05$ \\
Personally attends support group & \\
\hline Yes & $18.29 \pm 12.37$ \\
No & $23.67 \pm 13.06$ \\
\hline
\end{tabular}

negatively on the QOL in this population can guide clinical interventions by targeting caregivers with these higher risk characteristics. Herzer et al suggested that the caregivers and the patient make a joint contribution to both the patient's and the caregivers' QOL [22]. This highlights the need for family-based interventions that target both patients and their caregivers through a multidisciplinary approach that involves social workers, psychiatrists, nurse navigators, and primary care providers.

Previous studies have uniformly demonstrated that caregivers of patients with chronic disease are placed under significant financial, psychological, and physical strain [23-26]. A higher burden has also been linked to increased mortality among caregivers [23]. Though it is difficult to compare across studies, the caregivers in our cohort demonstrated a similar or perhaps even greater level of burden to that reported among caregivers of patients with acute brain injury (ZBI 21.7 \pm 10.1 ), Alzheimer's disease (ZBI 15.0 \pm 10.0 ), and advanced cancers $(12.0 \pm 8.5)$ [27]. Our study supports previous findings that the level of burden for caregivers was inversely related to the level of social support they received [11,28,29]. Though not directly measured in this study, previous studies have demonstrated that a patient's adherence to medical therapy depends heavily on the ability of the family unit to absorb the challenges $[30,31]$. Interestingly, we clearly demonstrated that participation in spiritual activities and social support groups may help reduce the level of burden for the caregiver. This underscores the fact that, as IBD practitioners, we should encourage caregivers to attend these group-based activities, which we have demonstrated in our previous study to be an effective outlet for patients and their caregivers [32].

Over one third of the caregivers in our cohort employed maladaptive coping patterns. The factors predictive of impaired coping skills included male gender, lack of involvement in spiritual activity or a support group, a personal history of psychiatric illness, and living in a different household from the patient. These characteristics could help identify caregivers who might require a greater psychological level of support. The utilization of maladaptive coping patterns has been linked to impaired social functioning and poor psychological wellbeing $[18,33]$. It is important for healthcare providers to identify patients or caregivers with maladaptive patterns, as there could be untreated depression. In our study, approximately $20 \%$ of caregivers reported having a personal history of mood disorder, whereas over $30 \%$ of caregivers were utilizing 
maladaptive coping patterns. Given that some maladaptive coping strategies (i.e., self-blame) may overlap with depressive symptoms, it suggests that we may miss approximately one third of caregivers who may have concomitant undiagnosed depression. In addition, as healthcare providers we need to help caregivers identify which coping strategies they naturally use, which strategies are effective and which ones are futile. This has been shown to facilitate maximally effective coping, even among caregivers who normally cope ineffectively [18]. Future studies will be needed to identify whether the caregiver's coping mechanisms also parallel those of the patient, and whether maladaptive mechanisms predict poorer long-term patient outcomes.

This study had several limitations. First, it had a crosssectional design that allowed for the assessment of coping skills only at one single point in time. To fully study coping patterns as a process will require a longitudinal study, as patterns of QOL, burden, and coping are likely to fluctuate with the patient's disease activity. Second, given that this was a survey-based study, there is likely to have been a recall bias, while the self-reporting aspect may have selected a subset of caregivers with a higher level of burden. Third, the terms utilized in our study, such as disease exacerbation, may not have been sufficiently specific. Exacerbation might include anything from increasing abdominal bloating to symptoms severe enough to require hospitalization. Therefore, various

\section{Summary Box}

\section{What is already known:}

- Chronic illness affects not only the patient but the entire family unit

- A high level of caregiver burden may result in poorer healthcare outcomes for the patient

- Household members of inflammatory bowel disease (IBD) patients have mental disorders more frequently compared with the general population

\section{What the new findings are:}

- Caregivers need an increased level of support during times of IBD exacerbation and when the patient has a higher level of disease severity

- Caregiver characteristics strongly predictive of the use of maladaptive coping mechanisms included male gender, lack of participation in spiritual activity or a support group, a personal history of psychiatric illness, and living in a different household from the patient

- Observance of religious activities and attendance at a support group appeared to improve quality of life and reduce perceived caregiver burden aspects of our comprehensive survey leave significant room for personal interpretation.

In conclusion, a large proportion of caregivers of IBD patients experience a high level of caregiver burden and a reduced QOL. The caregiver's QOL was most reduced when the patient had a higher level of disease severity or when their disease was actively flaring. The highest level of burden was associated with female caregivers, those of younger age or lower income level, having additional dependents in the household, patients with higher disease severity, and a personal history of psychiatric illness. Participation in religious activities and attendance at a support group appeared to improve QOL and reduce the perceived caregiver burden. This study suggests the importance of a multidisciplinary approach involving psychologists, social workers, and medical professionals to help caregivers absorb these daily life challenges and overcome their burden.

\section{References}

1. Shivananda S, Lennard-Jones J, Logan R, et al. Incidence of inflammatory bowel disease across Europe: is there a difference between north and south? Results of the European Collaborative Study on Inflammatory Bowel Disease (EC-IBD). Gut 1996;39:690-697.

2. SonnenberSonnenberg A, Wasserman IH. Epidemiology of inflammatory bowel disease among U.S. military veterans. Gastroenterology 1991;101:122-130.

3. Burckhardt CS, Woods SL, Schultz AA, Ziebarth DM. Quality of life of adults with chronic illness: A psychometric study. Res Nurs Health 1989;12:347-354.

4. Loftus CG, Loftus EV Jr, Harmsen WS, et al. Update on the incidence and prevalence of Crohn's disease and ulcerative colitis in Olmsted County, Minnesota, 1940-2000. Inflamm Bowel Dis 2007;13:254-261.

5. Casati J, Toner BB, de Rooy EC, Drossman DA, Maunder RG. Concerns of patients with inflammatory bowel disease: a review of emerging themes. Dig Dis Sci 2000;45:26-31.

6. Glozman JM, Bicheva KG, Fedorova NV. Scale of Quality of Life of Care-Givers (SQLC). J Neurol 1998;245 Suppl 1:S39-S41.

7. Sales E. Family burden and quality of life. Qual Life Res 2003;12 Suppl 1:33-41.

8. Lim JW, Zebrack B. Caring for family members with chronic physical illness: A critical review of caregiver literature. Health Qual Life Outcomes 2004;2:50.

9. Biegel D, Sales E, Schulz R. Family caregiving in chronic illness. Newbury Park, CA: Sage Publications, 1991.

10. Han B, Haley WE. Family caregiving for patients with stroke. Review and analysis. Stroke 1999;30:1478-1485.

11. Nguyen DL, Chao D, Ma G, Morgan T. Quality of life and factors predictive of burden among primary caregivers of chronic liver disease patients. Ann Gastroenterol 2015;28:124-129.

12. Akobeng AK, Miller V, Firth D, Suresh-Babu MV, Mir P, Thomas AG. Quality of life of parents and siblings of children with inflammatory bowel disease. J Pediatr Gastroenterol Nutr 1999;28:S40-S42.

13. MacPhee M, Hoffenberg EJ, Feranchak A. Quality-of-life factors in adolescent inflammatory bowel disease. Inflamm Bowel Dis 1998;4:6-11.

14. Gray WN, Graef DM, Schuman SS, Janicke DM, Hommel KA. 
Parenting stress in pediatric IBD: relations with child psychopathology, family functioning, and disease severity. $J$ Dev Behav Pediatr 2013;34:237-244.

15. Ferrans CE, Powers MJ. Quality of life index: development and psychometric properties. ANS Adv Nurs Sci 1985;8:15-24.

16. Zarit SH, Reever KE, Bach-Peterson J. Relatives of the impaired elderly: correlates of feelings of burden. Gerontologist 1980;20:649655.

17. Carver CS. You want to measure coping but your protocol's too long: consider the brief COPE. Int J Behav Med 1997;4:92-100.

18. Meyer B. Coping with severe mental illness: relations of the brief COPE with symptoms of functioning and well-being. J Psychopathol Behav Assess 2001;23:265-277.

19. Eckardt VF, Lesshafft C, Kanzler G, Bernhard G. Disability and health care use in patients with Crohn's disease: a spouse control study. Am J Gastroenterol 1994;89:2157-2162.

20. Vergara M, Casellas F, Badia X, Malagelada JR. Assessing the quality of life of household members of patients with inflammatory bowel disease: development and validation of a specific questionnaire. Am J Gastroenterol 2002;97:1429-1437.

21. Rabbett H, Elbadri A, Thwaites R, et al. Quality of life in children with Crohn's disease. J Pediatr Gastroenterol Nutr 1996;23:528-533.

22. Herzer M, Denson LA, Baldassano RN, Hommel KA. Patient and parent psychosocial factors associated with health-related quality of life in pediatric inflammatory bowel disease. J Pediatr Gastroenterol Nutr 2011;52:295-299.

23. Schulz R, Beach SR. Caregiving as a risk factor for mortality: the Caregiver Health Effects Study. JAMA 1999;282:2215-2219.

24. Cohen M, Katz D, Baruch Y. Stress among the family caregivers of liver transplant recipients. Prog Transplant 2007;17:48-53.
25. Bolkhir A, Loiselle MM, Evon DM, Hayashi PH. Depression in primary caregivers of patients listed for liver or kidney transplantation. Prog Transplant 2007;18:193-198.

26. Miyazaki ET, Dos Santos R Jr, Miyazaki MC, et al. Patients on the waiting list for liver transplantation: caregiver burden and stress. Liver Transpl 2010;16:1164-1168.

27. Higginson IJ, Gao W, Jackson D, Murray J, Harding R. Shortform Zarit Caregiver Burden Interviews were valid in advanced conditions. J Clin Epidemiol 2010;63:535-542.

28. Arango-Lasprilla JC, Moreno A, Rogers $\mathrm{H}$, et al. The effect of dementia patient's physical, cognitive, and emotional/behavioral problems on caregiving well-being: findings from a Spanishspeaking sample from Colombia, South America. Am J Alzheimers Dis Other Demen 2009;24:384-395.

29. Arango-Lasprilla JC, Nicholls E, Olivera SL, Perdomo JL, Arango JA. Health-related quality of life in individuals with spinal cord injury in Colombia, South America. NeuroRehabilitation 2010;27:313-319.

30. Bajaj JS, Wade JB, Gibson DP, et al. The multi-dimensional burden of cirrhosis and hepatic encephalopathy on patients and caregivers. Am J Gastroenterol 2011;106:1646-1653.

31. Beinart N, Weinman J, Wade D, Brady R. Caregiver burden and psychoeducational interventions in Alzheimer's disease: a review. Dement Geriatr Cogn Dis Extra 2012;2:638-648.

32. McMaster K, Aguinaldo L, Parekh NK. Evaluation of an ongoing psychoeducational inflammatory bowel disease support group in an adult outpatient setting. Gastroenterol Nurs 2012;35:383-390.

33. Carver CS, Scheier MF, Weintraub JK. Assessing coping strategies: a theoretically based approach. J Pers Soc Psychol 1989;56:267-283. 